\title{
OS SORTILÉGIOS DA (E)VIDÊNCIA
}

\author{
Pedro M. S. Alves \\ Centro de Filosofia da UL \\ Departamento de Filosofia FLUL
}

\section{As teses de Fernando Gil e a Fenomenologia}

Fernando Gil é, muito provavelmente, o filósofo português contemporâneo mais original. Não era um fenomenólogo por formação, nem nunca o foi, em toda a sua carreira intelectual. Os seus interesses intelectuais mais duradouros e constantes estavam concentrados em problemas relativos à epistemologia. No entanto, recebeu contínua e crescente inspiração de alguns autores da tradição fenomenológica, muito particularmente de Edmund Husserl. Como escreveu em La Conviction, "a análise epistemológica continua-se a ela própria através da fenomenologia do ato de conhecer". Lendo Husserl, Gil tratou de múltiplas questões, como as relativas à consciência do tempo, ao ego transcendental, à génese passiva e, mais importante que tudo, à teoria fenomenológica da evidência, tema a que dedicou uma obra de invulgar interesse e originalidade.

Enquanto epistemólogo, Gil ocupou-se dos problemas relativos à prova, por um lado, e dos relativos à experiência subjetiva da convicção, por outro. Escreveu duas monografias sobre esses temas: Preuves e La Conviction. ${ }^{2}$ No entanto, tanto os procedimentos objectivos da produção da prova como o crescimento subjetivo da convicção apontam para um tipo de protoexperiência em que a verdade se impõe por si própria, ao modo de uma presença

${ }^{1}$ La Conviction. Paris: Flammarion, 2000, p. 182.

2 Preuves. Paris: Aubier, 1988; La Conviction, ed. cit.. 
compulsiva e direta da realidade em e por si mesma. Esta protoexperiência designa-se por evidência. Ela é o nome para uma doação que impõe o seu conteúdo como verdadeiro e real, como index sui et veri, para lá de toda a prova relativa à verdade e de toda a verificação relativa à realidade. No livro que dedicou a este tema, o Traité de l'evidence, Gil considera Husserl como "o único pensador que desenvolveu em profundidade uma doutrina acerca da evidência". ${ }^{3}$ De fato, Husserl estabelece uma genealogia da evidência em obras como Erfahrung und Urteil, e, simultaneamente, uma sua descrição e qualificação epistémica em obras como Ideen e Cartesianische Meditationen. Dado que Gil pretende traçar aquilo que denomina como uma "arqueologia da evidência", a abordagem de Husserl é, assim, para ele, a "referência maior" no seu livro, entre tantos outros autores que discute extensivamente, como Duns Escoto, Ockham, Descartes, Arnauld, Malebranche, Kant ou Moritz Schlick.

Gil parte da assunção de que a evidência está encrustada no sistema perceção-linguagem: ela põe em conexão estesia e significação. De facto, a evidência não é nem simples intuição de um objeto, nem a sua simples representação linguística. Ela é, antes, a resolução de uma tensão que vai da antecipação do objeto pela representação significativa até a doação do objeto pela intuição; a evidência está, assim, ligada à satisfação, mais ou menos completa, de uma antecipação. Ela tem que ver com um movimento tensional, de que ela é o ponto terminal de relaxamento na satisfação. O par conceptual, fundamental para Husserl, da intenção significativa e do preenchimento intuitivo será, portanto, do ponto de vista de Gil, uma penetrante visão sobre as estruturas mais fundas da evidência.

A este respeito, Husserl recusou qualquer carácter afetivo à evidência, como Gil refere citando um texto de Ideen acerca de um suposto "sentimento de evidência". No entanto, para Gil, a correta recusa de Husserl de uma espécie de "sentimento místico" como marca da evidência é, no seu fundo, unilateral. $E$ isso por duas razões. Uma delas tem que ver com as teses próprias de Gil, a outra, quiçá mais fraca, refere-se às próprias asserções de Husserl que vêm matizar a sua recusa inicial. Para começar, a recusa husserliana é unilateral porque o par intenção/preenchimento - trata-se da tese de Gil - é como que um refinamento teórico de uma estrutura psíquica mais funda, baseada no par desejo/satisfação. Em segundo lugar, porque, apesar da sua recusa, o próprio Husserl sempre fala de um "contentamento no conhecimento" ou de uma "satisfação no preenchimento", ou também de um "esforço para a posse da própria coisa", reconhecendo, corretamente para Gil, que há como que "um contentamento próprio da evidência". ${ }^{4}$

3 Traité de l'évidence. Grenoble: Jérôme Millon, 1993, p. 8.

4 Ibid., pp. 10-11. 
Um outro par conceptual husserliano que Gil retém como fundamental para uma teoria da evidência envolve os conceitos, correlacionados mas não equivalentes, de "adequação" e de "apoditicidade", que Gil sobrepõe nos pares linguagem/perceção, intenção/preenchimento e, finalmente, desejo/satisfação. Como escreve, "a adequação enfatiza a presença preenchente do ser intuído, ao passo que a apoditicidade é como um outro nome para o conhecimento evidente. A apoditicidade - cume da Richitigkeit - aponta para o lado epistémico da evidência, enquanto a adequação aponta para a sua raiz ontológica". ${ }^{5}$

Intenção/preenchimento, como forma já intelectualizada de uma tensão mais arcaica que vai do desejo à satisfação, e adequação/apoditicidade, que captura o momento culminante da visão evidente, são, assim, os pares conceptuais centrais para a apropriação de Gil da teoria fenomenológica da evidência.

Quanto a esta, a teoria da evidência de Gil é desenvolvida em duas etapas principais. Primeiro, procede à dedução das categorias da evidência. De seguida, identifica o operador da evidência.

A respeito da primeira etapa, Gil apresenta os conceitos de atenção (com as suas raízes na orientação), de ostensão (enraizada no contato), de intuição (fundada na visão) e injunção (provindo da voz significativa), como estruturantes da evidência. A discussão das conceções de Husserl é muito importante no que diz respeito à análise da orientação, da atenção, do contato e, acima de tudo, da intuição (sobretudo em Ideen e em Erfahrung und Urteil). Relativamente à segunda etapa, a tese, ao fim ao cabo não tão surpreendente, é que a alucinação é o operador único da evidência. Segundo Gil, a relação estreita entre evidência e alucinação está, até certo ponto, encoberta devido ao predomínio da abordagem patológica da alucinação. No entanto, como escreve, este encobrimento não é total, pois "a evidência está toda ela trabalhada por uma linguagem alucinatória", havendo, por isso mesmo, uma "homologia - inesperada e não trivial - entre a descrição da evidência e a descrição da alucinação". ${ }^{6}$

$\mathrm{Na}$ unidade do operador alucinatório, Gil diferencia uma tripla eficácia. ${ }^{7}$ Primeiro, a daquilo a que chama operação-X (a "alucinação primitiva", de que fala Freud, do bebé alucinando o peito da mãe), que conecta desejo e sentimento de satisfação. Em segundo lugar, a operação- $\mathrm{H}$, intelectualizando o sentimento estésico na experiência de uma presença compulsiva, que é índice da sua própria realidade e verdade, operação que, metaforicamente,

\footnotetext{
5 Ibid.

6 Ibid., p. 249.

7 Ibid., pp. 259 e 261.
} 
se expressa nas imagens do "despertar", da "captura", da "luz" ou da "voz", e que, conceptualmente, se caracteriza pelos conceitos, aliás bem husserlianos, de "atenção", "ostensão" e "intuição". Finalmente, uma operação-E transforma esta presença em adequação, dando-lhe, portanto, a forma de uma auto doação que dispensa qualquer recurso à verificação (trata-se da Selbstgebung, de que fala Husserl), ao mesmo tempo que transforma a satisfação em apoditicidade, ou seja, numa certeza definitiva que dispensa e que está para lá do regime da prova.

Estes dois últimos operadores (não considerando as dimensões metafóricas) constituem, para Gil, o núcleo da análise fenomenológica de Husserl. Eles estão enraizados, porém, segundo as conceções de Gil, na eficácia de uma operação-X mais arcaica, alucinando a estesia a partir do desejo, a qual, até certo ponto, está para lá do alcance do método fenomenológico de descrição, todo ele concentrado na vivência de conhecimento e, por conseguinte, num momento de conceptualidade e de presença objetual que recobre esta suposta dimensão mais primitiva, onde não há ainda cisão entre significação e mundo de objetos, mas tão só o puro desejo alucinando a estesia em que obtém satisfação.

\section{Porquê um operador alucinatório para a evidência?}

A minha primeira questão tem que ver com as razões que levam Gil a propor um operador alucinatório para completar a teoria da evidência que encontra no corpus filosófico, e especialmente na fenomenologia de Husserl. Ou para o dizer pela forma inversa: que há ainda de insuficiente na teoria tradicional - máxime, na fenomenológica - da evidência?

A segunda questão que discutirei diz respeito à estratificação e à conexão das operações $\mathrm{X}, \mathrm{H}$ e E.

A alucinação é um operador, afirma Gil. Como ele próprio esclarece, o uso desse termo, aliás bem carregado, faz-se para caracterizar todo e qualquer dispositivo de transformação, operando sobre objetos e construindo um novo objeto. $O$ operador não tem por si próprio sentido, nem é ele próprio objeto. A referência de Gil são os operadores lógicos. O seu exemplo é o operador disjuntivo, que transforma duas proposições $p, q$ num novo objeto, $p \vee q$. O operador alucinatório tem, ainda, uma dimensão energética, uma "força", e uma outra figural, as quais exibem aspetos diferentes ao longo das transformações X, $\mathrm{H}$ e E.

Antes de descer a alguns pormenores desta estrutura, a questão primeira é, como disse acima, porquê completar a teoria da evidência por um tal operador alucinatório? Que falha vem isso preencher na teoria clássica da evidência? 
Julgo poder responder a isso da seguinte forma: a evidência não é a simples verificação de que um objeto se adequa a um conceito, ou que um estado de coisas se conforma a uma proposição - ela é, em simultâneo, a intensificação da estesia em presença e a concretização do conceito em inteligibilidade dessa presença, de tal modo que conceito e estesia se fundem um no outro na consciência apodítica da doação adequada de uma existência. A evidência exaure o pensamento, é como que a sua extraversão, que só deixa subsistir a própria coisa na sua existência inteligida e plena, sem perfis, sem obscuridades, sem restos, ou, como Gil não hesita em dizer, na sua presença "numenal". Ora se isto é bem a evidência, então, para isto, a teoria clássica não tem uma boa descrição.

Dou apenas dois casos que me parecem emblemáticos.

O primeiro é o da teoria kantiana dos esquemas. Como Kant o define, o esquema é um "monograma da imaginação" que permite construir para um conceito imagens correspondentes. A relação entre conceito e imagem é a de ilustração - a imagem é subsumida no conceito e aparece, por via dessa subsunção, como uma figuração sensível daquilo que está conceptualmente pensado. Acerca desta função, Kant nada mais diz a não ser que este jogo da imaginação é uma arte escondida nas profundezas da alma. Uma outra asserção é, porém, mais elucidativa, a saber, quando afirma que a esquematização assenta numa dimensão que é simultaneamente sensível e intelectual, isto é (nessa passagem, Kant está a falar dos conceitos puros), numa instância que seja, por um lado, homogénea à categoria e, por outro, homogénea às representações da sensibilidade. Isto significa que o esquema unifica significação e estesia e as sobrepõe de tal modo que daí resulta uma estesia conceptualizada ou um conceito sensibilizado, por assim dizer. Ora isso, esse poder de ver na estesia o conteúdo do conceito é bem um poder de alucinação. Kant, porém, passa-lhe ao lado e enfraquece-o de duas maneiras. Enfraquece-o, primeiro, ao considerar que o esquema fornece apenas uma imagem ilustradora, sem conteúdo de realidade. Segundo, ao entender a relação do esquema com a posição de existência de um objeto como uma relação de subsunção de um diverso sensível num conceito, coisa que mantém a dualidade da significação e da estesia, como se apenas houvesse entre elas uma relação de sobreposição, quando, na verdade, se trata de uma verdadeira imisção de estesia e significação. A questão central não é, por outro lado, nem tocada por Kant: o poder de figurar, de estetizar a significação, de ver sensivelmente um conteúdo conceptual, e de ver não uma simples ilustração, ou seja, uma imagem, mas de passar do momento figural à própria coisa na sua presença e na sua existência. Essa é bem a função do operador alucinatório, de que fala Gil, e que a doutrina kantiana dos esquemas, demasiado presa à dualidade não 
resolvida da sensibilidade e do entendimento, acaba por não tomar verdadeiramente em conta.

O outro caso notável é precisamente a teoria husserliana do preenchimento, Erfüllung, mais precisamente, da relação dinâmica de preenchimento de que fala a sexta investigação. Na relação dinâmica de preenchimento, Husserl surpreende uma tensão que vai da representação signitiva de um objeto até o ato intuitivo que apresenta o próprio objeto visado e como que dá satisfação à antecipação que prolonga a intenção até o momento culminante da doação. O contrário deste relaxamento da tensão é a conexão dos atọ signitivo e intuitivo segundo a relação oposta, em que o intuitivamente dado não é conforme ao que fora signitivamente antecipado, conexão que Husserl designa, muito pertinentemente, por Täuschung, ou seja, por algo que poderíamos, no contexto, traduzir por deceção ou desilusão. Como bem viu Gil, há algo como uma expectativa e uma antecipação na intenção, a qual é satisfeita ou dececionada no preenchimento, que realiza o encaixe dos atos signitivo e intuitivo. Este encaixe é possível porque o ato dito intuitivo mostra aquilo mesmo que fora antecipativamente significado, mas mostra-o, justamente, sob um regime totalmente diferente da intenção signitiva. Aí, temos um significar encrustado na linguagem; aqui, temos um ver da coisa mesma, para lá da dualidade da intuição e do conceito. Este ver aquilo, ou aquela coisa que fora visada, esta apreensão de um sentido sob o registo da figuração sensível, é, verdadeiramente, a força do operador alucinatório em que, numa linguagem paradoxal, que Gil não hesita em utilizar quando cita Bion, os pensamentos se tornam coisas, e as coisas são patenteadas por uma intensificação e por uma intelectualização das estesias.

Pois bem, quando procede à análise desta conexão de preenchimento, a doutrina canónica de Husserl, pese embora algumas análises mais subtis, é que ela se analisa do seguinte modo: há, de um lado, um ato signitivo, que visa um objeto ou estado de coisas a partir de um sentido nominal ou proposicional, e, do outro, um ato intuitivo que, por sua vez, se analisa como constituído por um sentido de apreensão e por certos conteúdos primários (o nome de Husserl para os dados estésicos) que realizam a função de apresentação da própria coisa visada. Ora como Husserl supõe que este segundo ato contém um sentido em tudo idêntico ao do ato signitivo (no caso do preenchimento confirmante) e que é, portanto, inteiramente separado do material estésico, a sua análise dá flanco ao argumento do terceiro homem. Na verdade, se um ato signitivo se preenche pela conexão com um ato intuitivo, mas se este ato intuitivo contém um sentido idêntico ao do ato signitivo, para que este se conectasse com o material estésico, necessitaríamos de um novo ato que animasse esse material com um sentido de apreensão, e assim sucessivamente, posto que, para Husserl, a conexão se dá entre sentido e sentido, não se chegando 
nunca a um sentido encarnado e perpassado pelas estesias, que pusesse fim a esta regressão.

Hubert Dreyfus foi dos primeiros a assinalar esta insuficiência na doutrina husserliana do preenchimento. Quanto à conexão entre sentido e material estésico, Husserl fala de animação (Beseelung), apreensão (Auffassung) e, na primeira edição das Investigações, de interpretação (Deutung). O sentido "anima", "apreende" ou "interpreta" a função estésica, produzindo a mostração de uma coisa. Tudo isto, até certo ponto, são metáforas que voltejam em torno de uma dificuldade maior: descrever um sentido que não se sobrepõe à função estésica, mas que se expressa e se articula dentro das próprias estesias e produzindo nelas a figuração de um objeto. Este sentido já não seria analisável como idêntico ao do ato signitivo. Nas suas investigações posteriores sobre o noema percetivo, Husserl aclarou mais a fundo esta peculiaridade. No entanto, isso permanece um ponto obscuro das análises fenomenológicas. O fator crucial é mostrar como o sentido opera sobre a estesia, de modo a que não haja duas coisas, a significação e o material estésico, mas visão do sentido na estesia e, através dela, da coisa a que esse sentido intencionalmente se reporta. Esta função figurativa e apresentadora de uma presença, este sentido que se realiza não num visar, mas num ver, e num ver direto, é justamente aquilo que o operador alucinatório pretende identificar.

Há, pois, segundo creio, boas razões para chamar a atenção para uma operação alucinatória inscrita na evidência.

Quanto aos aspetos de pormenor sobrelevados por Gil, principalmente no Quadro VII do Traité de l'evidence, serei mais breve.

A primeira observação exprime uma dúvida e uma sugestão. Como Gil escreve, por força das operações $\mathrm{H}$ e $\mathrm{E}$, um dado sensorial e linguístico, é transformado em inteligibilidade, pela operação $\mathrm{H}$, e a inteligibilidade em satisfação do espírito. A operação $\mathrm{H}$ "conduz a uma presentação do inteligível", como escreve mais à frente. ${ }^{8}$ Ela trabalha sobre o objeto 1 da operação $\mathrm{X}$, que produz um dado linguístico e sensorial. ${ }^{9}$ Ora, examinando a segunda parte do quadro, onde se expõe o resultado da operação $H$, ligada à inteligibilidade, verifica-se que há uma quadrícula em branco, não preenchida, na coluna que, sob a rubrica "conceito", alinha atenção, ostensão e intuição. Seguindo na direção horizontal, o quadro em branco está ligado à voz, ainda na operação $H$, e prosseguindo a linha vertical em direção ao objeto da operação $X$, verifica-se que ele se liga ao aspeto progressivo, na linguagem, e à audição. Nesta circunstância, sabendo que a operação $H$ tem que ver com a presentação

9 Ibid., pp. 218-219. 
do inteligível, não seria de esperar que a quadrícula em branco completasse o par progressivo/audição/voz com a categoria da "compreensão"? Na verdade, esta linha do quadro tem que ver com aspetos ligados ao elemento linguístico, e toda a operação $\mathrm{H}$, como dissemos, com a inteligibilidade. Assim sendo, o ponto culminante do processo que passa por audição e voz seria, naturalmente, a compreensão, que, enraizada na linguagem, dá um sentido inteligível à pura fixação sobre uma presença balizada pelas categorias - por si só intelectualmente cegas - da ostensão, da intuição e da atenção. Isso seria, dito husserlianamente, o momento da Auffassung, pela qual a compreensão de um sentido de apreensão anima os conteúdos estésicos para os quais o ego se volta, na passividade, na consideração atenta do que o afeta nos campos sensíveis.

A segunda observação é de conjunto. Gil procede a uma arqueologia da evidência. A estrutura mais arcaica que deteta é o par desejo/satisfação. Ele contém toda uma tensão e uma energética. A ideia é que as camadas superiores se arquitetam sobre esse solo e continuam a receber dele a sua força, como os movimentos tectónicos de fundo sacodem e abalam as estruturas superiores. Assim, é ainda essa tensão profunda que opera no arco já conceptual que vai da significação à intuição, dando origem à síntese de preenchimento entre visado e dado. E é ainda a satisfação arcaica do desejo que assume a sua forma paroxística e final na alucinação do existente, em que o pensamento (já não o puro desejo ligado à simples estesia) descansa na adequação e na apoditicidade da "posse" da "própria coisa", para usar uma expressão cara a Husserl. No entanto, se isto é assim, a alucinação do existente é como que o cativeiro do pensamento, o seu ponto de embotamento e exaustão extática, ante uma presença obsidiante que pura e simplesmente o aniquila. Na evidência, o pensamento cessa, para lá dela há apenas quietação. Tem esta evidência um valor epistémico? Husserl viu nela como que o alfa e o ómega de toda a ciência. Descartes, antes dele, vira na certeza da evidência o único ponto de partida da ciência, embora ela se fosse atenuando à medida que a ordem das razões se desenvolvia e, do ego e de Deus, se passava ao conhecimento do mundo físico nas suas particularidades. Mas, ao contrário de todas as doutrinas da evidência, não haveria que sustentar que o pensamento se institui pelo registo do signo? Não haveria que sustentar que o pensamento só alcança autonomia quando, em vez dessa tendência para nähe der Sachen bleiben, para estar junto das coisas, como diria Husserl, permanecer definitivamente Sachefern, ou seja, distante, na instância do signo e das suas manipulações? No quadro da arqueologia da evidência proposta por Gil, tal pensamento seria um pensamento insatisfeito, que diferiria para sempre o momento da quietação. Mas não é isso justamente o pensamento? E como exigir que toda a riqueza e articulação do pensamento possam ser reconduzidas à evidência doadora, à alucinação do existente? Não alcança o pensamento, pelas regras de manipulação dos signos, 
regiões de todo em todo arredadas da relação com a evidência? Não teriam, ao fim ao cabo, razão aqueles que desde sempre suspeitaram dessa miragem da evidência, não teriam, afinal, razão um Leibniz ou um Hilbert, para falar apenas de dois nomes maiores?

\section{A força alucinatória}

A lição do Traité de l'evidence contém uma ambiguidade quando a uma ponderação do valor epistémico da evidência. A sua tese é que o ego é, digamos, a matriz e o padrão da alucinação da existência. Como o diz em vários lugares do tratado, quer o ego substancializado, à maneira cartesiana, quer a totalidade do fluxo de consciência, à maneira husserliana, são, um e outro, alucinações do ponto de vista. Como escreve, "o sujeito não é mais que um centro de perspetivas, o interface do pensamento com o mundo". 10 A evidência de um eu substancial ou da totalidade do fluxo é, para Gil, a forma canónica da evidência alucinatória da existência. A evidência lógica é já uma forma segunda. Ela opera sobre objetos construídos por processos metódicos. Como tal, em certo sentido, a evidência, nesta forma mais primitiva da alucinação do existente, a qual tem no ego a sua forma matricial, é como que alucinação do invisível - ela vai para lá do dado e põe, nele e por ele, algo que simplesmente o excede.

Seria possível, pois, "desconstruir" esta evidência hiperbólica, que patenteia uma existência inexaurivel, ou seja, seria possível desfazer os seus sortilégios pondo a descoberto os processos da sua produção. Hume fê-lo no Treatise para o ego substancial. Kant fá-lo-á também nos paralogismos da sua Kritik. Gil dá uma leitura brilhante da crítica kantiana da ilusão substancialista, mostrando uma correspondência surpreendente entre as asserções kantianas, sobretudo da primeira edição, e a sua descrição das operações $H$ e E. Ao mesmo tempo, Gil permanece atento a que é, para Kant, o núcleo mais fundo dessa ilusão: a consciência indeterminada que temos da nossa existência, na unidade da aperceção, existência que, como ele afirma comentando uma célebre nota de Kant, é uma existência pré-categorial e, por isso mesmo, indeterminável e inefável. Como se, ante a consciência indeterminada de que existo, a miragem alucinatória consistisse em levar essa existência a uma, afinal impossivel, intuição adequada que a pusesse a descoberto nas suas determinações. Temos aqui, portanto, na esteira de Kant, uma bifurcação entre apoditicidade e adequação: a consciência da minha existência é apodítica, mas essa existência, porque categorialmente indeterminável, jamais se poderá 
volver numa intuição adequada e numa completa determinação. O. mesmo fará Husserl, pelo seu lado, quando, nas Cartesianishe Meditationen, separará nitidamente entre apoditicidade e adequação: a certeza de si é apodítica, mas a intuição de si próprio é e permanecerá para sempre uma progressão sem fim que será, portanto, inadequada. Como se a alucinação da existência, com o seu núcleo de apoditicidade, tombasse sobre algo absolutamente certo, no sentido de que não pode não ser no próprio momento em que é intuído, mas como se essa existência apodicticamente dada fosse um objeto excessivo que jamais pudesse ser percorrido pelos próprios processos cognitivos que conduziram à sua posição. É precisamente nesse sentido que dissemos que esta evidência primitiva é alucinação do invisível - ela põe algo que excede toda a determinação.

Não é, porém, sobre as subtilezas da autoconsciência que quereria falar, em jeito de reflexão final. Queria falar sobre esta mesma alucinação do invisível numa outra sede, a meu ver tão primitiva quanto a autoconsciência. Se há uma alucinação psicológica, que transmuta o ponto de vista em ego substancial, há também como que uma alucinação cosmológica, que põe a existência do mundo como contraparte correlativa à alucinação do ponto de vista. Mais que a alucinação psicológica, ela realiza uma intensificação suprema da presença extática do existente. A sua expressão mais pura é o Es gibt, o there is ou o il y $a$, ou seja, um "haver" ou um "há qualquer coisa", que realiza uma consciência apodítica de uma existência total e plena, antes ainda de qualquer modalidade de mostração que a penetre e a desagregue em intuições parciais. Husserl falou de uma Urdoxa, ou seja, de uma crença primitiva passiva, enquanto pré doação do mundo enquanto tal. A tensão para a posse por via da intuição determinadora produz a alucinação de um mundo espacial e temporal, onde é possível recortar existências singulares e trazê-las ao regime da intuição. A evidência do singular, de que fala Gil no último capítulo do seu tratado, tem por detrás esta consciência apodítica de uma existência impartida, plena, e a alucinação da espácio-temporalidade como forma de conjunto da totalidade do existente. Mais uma vez, seguindo as pistas de Gil, seria possível ler Kant como o crítico desta alucinação, nomeadamente, na sua estética transcendental. Aí se mostra que espaço e tempo não são coisas nem propriedades de coisas, mas simplesmente a projeção do nosso modo de intuir, projeção que, quando coisificada, produz justamente a alucinação de um mundo como totalidade de existências num espaço e num tempos cósmicos.

A enorme força sugestiva do tratado de Gil consiste em, simultaneamente, nos mostrar o que é a evidência e em nos abrir as portas para a crítica dos seus sortilégios encantatórios. 


\begin{abstract}
While not a phenomenologist, Fernando Gil was highly interested in some aspects of Husserl's work. One of these aspects was Husserl's theory of evidence. In a notable book entitled Traité de l'évidence, he developed a throughout theory of evidence, paying close attention to the most important insights Husserl exposed in his works. Gil's theory of evidence is at the same time rooted in Phenomenology and extended beyond it, inasmuch as he locates the first dimension of evidence in a primitive stratum hallucinating aesthesia from desire. Accounting for evidence as a threefold process, going from aesthesia to presence, and then to the intellectual grasping of an individual object, the most interesting feature of his theory is the interpretation of evidence as a hallucinating process, encompassing all strata of sensitive, perceptive, and conceptual life.
\end{abstract}

